\title{
Embedded Flexibility Strategies and Diversity within National Institutional Frameworks: How many Flexibility Profiles are in the German Model?**
}

The varieties of capitalism approach $(\mathrm{VoC})$ and the related research assume that German firms adopt an internal flexibility profile that corresponds with the national institutional framework. Recent empirical studies, however, have found substantial diversity in realized firm-level strategies. This article investigates the actual distribution of flexibility practices in German establishments. Latent class analysis revealed four flexibility profiles, including a dual profile that combines internal and external flexibility as well as a low flexibility profile that is characterized by an overall low importance of flexibility practices. The distribution points to significant diversity of flexibility profiles within the German economy and emphasizes the role of industry and firm size as crucial factors for the externalization of flexibility and a growing dualism within the German economy.

Key words: German model, internal and external flexibility, temporary agency work, outsourcing; latent class analysis (JEL: C38 L60 L86 O15 P10)

* Stefan Kirchner, University of Hamburg, Welckerstraße 8, 20354, Hamburg, Germany. Email: stefan.kirchner@uni-hamburg.de.

** The author is grateful to Jürgen Beyer, Lutz Bellmann and the whole MINO-project team for support and cooperation in the project. Also the author would like to thank the participants and the organizer of the "9. Jahrestagung des Arbeitskreises Empirische Personalund Organisationsforschung (AKempor)" and Marc Casper for critique and advice on earlier versions of this paper. The research presented in this paper is based on a joint project of the University of Hamburg and the Institute for Employment Research (IAB) funded by the German Federal Ministry of Education and Research (BMBF) and the European Union's European Social Fund (ESF).

Article received: March 29, 2012

Revised version accepted after double blind review: December 23, 2012. 


\section{Introduction}

Under the label "German model" characteristics of the German economy have been in the focus of several researchers (cf. Albert, 1992; Esser, Fach, \& Simonis, 1980; Jürgens, Krzywdzinski, \& Teipen, 2006). According to the varieties of capitalism approach $(\mathrm{VoC})$ and the related literature, firm strategies are embedded in the national institutional context and the respective socio-economic environment (Hall \& Soskice, 2001). In this and related research approaches, German firms are expected to pursue internal flexibility practices (Streeck, 1991; Tüselmann, 1996; cf. Whitley, 2007; Jackson \& Deeg, 2008). Yet, especially in the German employment system, considerable changes towards external flexibility patterns have taken place. Examples for prominent practices of external flexibility are temporary agency work (TAW) and outsourcing. In the 1990s both practices were introduced by a considerable share of firms. One might expect that this development has led to a substantial diversity of flexibility patterns within the German economy.

This paper aims to uncover different flexibility patterns in German firms. In addition, it accounts for a possible tendency to replace or combine traditional practices of internal flexibility with novel external practices such as TAW and outsourcing. Thus, this paper contributes to the growing literature on strategic diversity within market economies (Herrmann, 2008; Crouch, Schröder, \& Voelzkow, 2009; Lange, 2009; Barry \& Nienhueser, 2010). It also relates to research that has emphasized the externalization of flexibility in general (Kalleberg, 2001) and a recently growing dualism on the German labour market in particular (Palier \& Thelen, 2010; Hassel, 2012).

The debate arguably suffers from two major shortcomings. Firstly, there is a need to address the underlying segments of diversity conceptually. A conceptual approach of multi-level embeddedness of firms in national economies is proposed here. This approach emphasizes the influence of industry and firm size on particular flexibility profiles. Secondly, there is an empirical gap concerning firm-level data and respective analysis. Both are needed to assess firm-level diversity within the German model.

The research approach was guided by three main questions: (1) Are there different profiles in Germany that combine flexibility practices? (2) What implications can be drawn for the idea of a particular German model of flexibility? (3) What role do particular segments play in the distribution of flexibility profiles?

The analysis is based on a telephone survey data set of German establishments in highly innovative industries collected in the second half of 2010.The argument of the article is structured as follows:

Section 2: The general theoretical approach of the VoC literature is introduced and discussed under the aspect of flexibility on the firm level. The recent debate on diversity within national frameworks is introduced and complemented with the concept of societal sectors and the industry culture approach. Section 3: Conceptual and empirical approaches towards flexibility practices are discussed and a concept of flexibility profiles is developed. Section 4: Based on the raised conceptual issues and the concept of flexibility profiles, latent class analysis (LCA) was conducted. The analysis reveals different combinations of flexibility practices. Additionally, multiple correspondence analysis (MCA) was computed to map the underlying distributions and re- 
lations. Section 5: The empirical results are discussed and related to the introduced conceptual considerations.

\section{The German model}

In the VoC literature, Germany is depicted as a model case of a so-called coordinated market economy (Hall \& Soskice, 2001; cf. Amable, 2003; Whitley, 2007). The basic argument implies that institutional conditions in Germany and the USA differ. German firm strategies are expected to differ from those in the USA because institutional conditions support specific firm-level strategies. This juxtaposition has been very influential for international comparisons of foundations of competitive economic successes (Jackson \& Deeg, 2008).

While there are variations within the literature concerning how and why firms are connected to the institutional framework of this German model, there is some agreement on the foundations of the general patterns. The model thus consists of specific institutional characteristics (Hall \& Soskice, 2001) as well as of corresponding firmlevel strategies and practices (Sorge, 1991; Streeck, 1991).

One key component of the German case has been the particular German employment system and a respective labor market structure (see Tüselmann, 1996; Jürgens et al., 2006). On the firm level the respective employment practices are generally understood to rely on the long-term commitment of employers and employees. Traditionally, German firms are expected to draw on internal flexibility practices to cope with volatile economic environments (Streeck, 1991). It is argued that external flexibility is foreclosed institutionally. The default flexibility practices in this perspective are the shifting of (so called polyvalent) qualified workers from one workplace to another or simply demanding overtime from the employees at hand.

\subsection{Flexibility and diversity}

Building on early seminal contributions (Streeck, 1991; Herrigel, 1996) the VoC approach has catalyzed and partially incorporated the debate about the German model of capitalism. VoC is introduced as a firm-centered approach with companies as primary economic agents (Hall \& Soskice, 2001). However, key assumptions are made on the level of entire national economies. The actual distribution of patterns on the firmlevel is not central. Hall and Soskice (2001, p. 34) acknowledged the existence of regional as well as sectoral layers that increase diversity and argue that institutional structures do not fully determine corporate strategies. At the same time the authors maintain that, on a national level, the average firm is pushed towards specific strategies. The extent of variations and its implication for the national institutional framework argument were not addressed.

Recently, a number of studies has emphasized the role of diversity within market economies (Herrmann, 2008; Crouch et al., 2009; Lange, 2009; Aoki \& Jackson, 2008 also Herrigel, 1996, 2010; Kirchner, Beyer, \& Ludwig, 2012). A general finding of this literature is that various strategies can be found, conflicting with the general prescriptions of the German institutional framework and the theoretically expected patterns. For some cases a strong local embeddedness is the source and cause of alternative 
strategies. Other examples are characterized by the reach of international markets or industry models (Herrmann 2008; Crouch et al. 2009; Crouch \& Voelzkow, 2009).

Firm-level variation within national frameworks poses a fundamental challenge to basic theoretical pillars of the VoC literature (see Barry \& Nienhueser, 2010). The majority of studies in the field of $\mathrm{VoC}$ related literature is based on case studies or macro data. Thus there is a significant lack of quantitative firm-level research. From the existing studies alone it is difficult to grasp the actual scope of the national institutional framework debate in general and for the German model argument in particular. The current state of the German model needs to be measured and mapped in order to advance the debate.

Obvious starting points for mapping the current state of the German model are basic economic segments in respect of industries and firm size. There is a strong research tradition that has dealt with industry or sectoral diversity as being rooted in so called macro cultures (Abrahamson \& Fombrun, 1994) or industry cultures (Schreyögg \& Grieb, 1998; Bühler, Cachelin, \& Maas, 2010; see also Krause, 2013). Scholars of this literature argue that common cultural schemes provide default strategies or organizational practices in particular industries. Firms will stick to common patterns because those are generally expected or alternative patterns are not considered to be tolerable alternatives.

Complementing the idea of industry cultures as one layer of a given nation's institutional framework, firm size should be emphasized as another important factor of diversity. Berghoff (2006) stressed that within the VoC-debate there has been a bias towards large firms. Other authors have also raised the importance of smaller firms for employment and economic activity in Germany (see also Streeck, 1991; Herrigel, 1996, 2010). Berghoff (2006) acknowledged that beside some similarities between larger and smaller companies, substantial differences can be found as well. He argued that family owned and family operated small and medium size enterprises (SMEs) with a cooperative orientation towards their workforce and strategies of long-term quality competition comply with the traditional model of German SMEs. In contrast German SMEs are less well included in the industrial relations system than their larger counterparts. So far, the default applications of the VoC argument have generally underestimated the importance of SMEs for Germany's industrial power.

In the light of the current discussion, an instrumental theoretical concept needs to address organizational adaptation in ambiguous, layered, potentially overlapping and contradicting institutional environments. The VoC literature lacks a comprehensive theoretical concept that relates assumptions about general default strategies to empirical findings of diversity. A solution to this problem of diversity is a perspective of multi-level embeddedness of organizations. This issue relates to current findings that is carried out in the field of innovation research that has identified specific industrial sub-sectors within national economies (Hirsch-Kreinsen, Ittermann, \& Abel, 2012). To capture basic institutional segments underneath or across national economies, the concept of societal sectors proposed by Scott und Meyer (1991) is helpful. ${ }^{1}$

1 The more clear cut definition avoids some of the problems with the similar organizational field concept by Powell and DiMaggio (1983; cf. Wooten \& Hoffman, 2008). 
The societal sector approach refers to the economist's concept of industry that is built on the notion of substitutability of product or service and demand interdependence. The concept can also be extended to other interconnected organizations that follow a similar shared orientation. Accordingly, the different parts and sub-parts of the industry-categories or overlapping firm size classes can be treated as distinct societal sectors within a given national institutional framework.

\subsection{Changing models: Advancing external flexibility until the 1990s}

The traditional German model concept was developed to account for the situation in West Germany in the 1980s. It has been observed that the state of the German model has been shaped by significant changes since then. Accordingly the VoC assumptions can only be treated as a theoretical starting point for an evaluation of the current state of the German model in terms of flexibility. In recent years a fundamental evolution or erosion of the traditional German model has been observed by several authors (Beyer \& Höpner, 2003; Kitschelt \& Streeck, 2004; Beyer, 2007; Bosch, Haipeter, Latniak, \& Lehndorff, 2007). The economic crises in 1992/3 and the socio-economic effects of the reunification process as well as the forces of globalized markets and their effects on production and innovation models have been identified as underlying causes of organizational changes of German firms (Bosch et al., 2007).

On the institutional level especially the employment system is believed to be subject to a process of liberalization (Hall \& Thelen, 2009; Schneider \& Paunescu, 2012) that results in a growing dualism in the German labor market. Insider and outsider distinctions that have traditionally characterized the German economy (Gallie, 2007) become more pronounced as a consequence of policy reforms (Palier \& Thelen, 2010; Hassel, 2012). The growing dualism as a consequence of institutional change has its counterpart on the firm-level. Here an increased externalization of flexibility (DavisBlake \& Uzzi, 1993; Kalleberg, 2001) can be observed. Two developments on the firm-level mark this substantial shift away from previous internal flexibility practices, which were traditionally believed to be characteristic for the German economy. These are the growth of temporary agency work (TAW) (Zeitarbeit or Leibarbeit) and the outsourcing of firm functions that were previously provided internally:

(i) Temporary Agency Work (TAW): The growth in non-standard employment forms poses a challenge to traditional strategies (Bellmann, Hohendanner, \& Kühl, 2008; Lengfeld \& Kleiner, 2009). Especially TAW shows a considerable difference to standard employment as it lacks a reliable mutual expectation of continued employment (see Ashford, George, \& Blatt, 2007). While absolute numbers for temporary employment are still relatively low, Germany has experienced steady growth, particularly since 2004. Even the last economic downturn has only temporarily interrupted this development (see Bouncken, Bornewasser, \& Bellmann, 2012).

Being a resource for short term organizational flexibility is an important reason but not the only one. There are many different reasons for firms to use TAW (Alewell \& Hauff, 2011, p. 15). While some firms employ high qualified workers as a source of short-term competence, others introduce TAW as part of their recruitment strategy or as vacation replacement for regular employees. TAW thus has become an important 
employment strategy element (Nienhüser, 2007). ${ }^{2}$ However, Holst et al. (2010) delineate the usage of TAW as a significant shift in general employment practices. The authors emphasize that it has a disciplining effect on the core work force. Following this argument, TAW also appears as a fundamental misfit considering the assumption of long-term strategies and a system built on worker loyalty and commitment that has traditionally been at the core of the German model.

(ii) Outsourcing: Alongside shifting employment patterns and especially the reorganization dynamics in the 1990s, a concentration on core competences has been promoted (Kinkel \& Lay, 2003). In contrast to the theoretical attention paid to outsourcing in the general debate on workplace transformation and socio-economic changes, very little solid data is available concerning the actual extent and its effects. The few available studies show that a substantial number of firms has outsourced different functions to subcontractors (Kinkel \& Lay, 2003). However, it has also been observed that the outsourcing trend stagnated in 2000 (Görzig, Kaminiarz, \& Stephan, 2005).

Similar to temporary agency work, a variety of reasons for outsourcing can be found. Many firms subcontracted service functions that were once part of the company manly for reasons of cost-cutting. This applies to many auxiliary functions such as canteen, security or cleaning services. But this also includes aspects that are closer to the core business such as development or production activities and IT services (see Kinkel \& Lay, 2003; Görzig et al., 2005). Thus for many firms outsourcing decisions pose general strategic alternatives predominantly concerning non-core functions. The debate furthermore emphasizes the importance of outsourcing for relocating firm functions (to other countries) (Ahlers, Öz, \& Ziegler, 2007; Kinkel \& Maloca, 2010). In terms of flexibility though, the practice of outsourcing to subcontractors in order to cope with temporary increased workload is central. This aspect has not been in the focus of previous research.

\section{Relating flexibility practices introducing flexibility profiles}

Flexibility has been a key issue for employment studies for a long time. Thus, arguments can be built on the findings and conceptual considerations of existing research. For scholars of organizational flexibility, it is not "big news" at all that there are different patterns of flexibility. It is one shortcoming of the $\mathrm{VoC}$ advocates and the related literature not to include existing findings in this field systematically and not to relate the theoretical assumptions to firm-level evidence.

Dealing with different flexibility practices eventually raises questions about their relation. Several authors have proposed concepts to classify different flexibility practices. One of the earliest and widely cited schemes has been proposed by Atkinson

2 Other forms of so called "atypical" or "non-standard" employment forms (Ashford et al., 2007) are often found to serve many purposes other than organizational flexibility - e.g. part time work as a result of gender-arrangements and fixed-term contracts as a form of extended trial period for younger employees (Szydlik, 2008; Dütsch \& Struck, 2011; for international perspective see Marsden, 2010). Other forms of non-standard employment may contribute to a general climate of increasing employment instability. 
(1984; cf. Kalleberg, 2001). The author distinguishes functional and numerical practices as well as internal and external practices of flexibility. Crossing both dimensions, a simple two-by-two table of possible sub-categories is produced (see Table 1). Other authors have proposed more comprehensive taxonomies encompassing further practices and sub-categories (see Keller \& Seifert, 2006; Hohendanner \& Bellmann, 2007; Dütsch \& Struck, 2011). While those approaches might offer more differentiated depictions of flexibility practices, the original internal-external/functional-numerical table is sufficient for this paper. It includes the basic dimensions that are more or less shared by all other approaches.

Table 1: Classification of flexibility practices

\begin{tabular}{lll}
\hline & Numerical & Functional \\
\hline Internal & $\begin{array}{l}\text { Working Time (overtime, short-time } \\
\text { work, ...) }\end{array}$ & $\begin{array}{l}\text { Shifting of workers between } \\
\text { workplaces }\end{array}$ \\
\hline External & Temporary Agency Work (TAW) & Outsourcing to subcontractors \\
\hline
\end{tabular}

Source: Own depiction, adopted from Atkinson, 1984, cf. Kalleberg, 2001; Hohendanner \& Bellmann, 2006; Keller \& Seifert, 2006

Following the introduced table a shifting of workers between different workplaces such as different production lines or tasks areas can be categorized as a practice of internal-functional flexibility. Working time flexibility can be understood as internal numerical practice. As outlined above, these two internal flexibility practices are viewed as basic pillars of the German model on the firm-level (cf. Streeck, 1991). TAW, in contrast to these traditional practices, constitutes an important example of external-numerical flexibility. Analogical, a major external-functional practice of flexibility is posed by outsourcing activities that had been carried out within the firm previously.

To understand the new role of TAW and outsourcing on the firm level, it is necessary to relate it to other flexibility practices (see Kalleberg, 2001). In the current literature there is a substantial lack of empirical evidence in both national and international research concerning the possible combinations of different flexibility practices (see most recently Dütsch \& Struck, 2011). The few studies that were undertaken usually investigated the direct relation of particular flexibility practices (Hohendanner \& Bellmann, 2006; Dütsch \& Struck, 2011). Using regression analysis in large samples of firms, it is tested whether particular flexibility practices are characterized by a direct substitutive or complementary relation. In contrast to these previous approaches, this paper follows the idea of particular organizational configurations (see Fiss, 2007). The configuration of particular firm-level practices can be an indicator for a particular firm-level profile. Rather than testing for associations throughout entire populations, it is here proposed that populations - like industries or national economies - contain distinct firm-level profiles of flexibility that combine flexibility practices in a particular way. So this approach departs from the substitutive-complementary-research tradition by understanding flexibility configurations as basic segments within a given population. This paper proposes that each configuration is potentially characterized by a specific substitutive or complementary relation among the included flexibility practices. 
Accordingly, the idea of specific configurations of flexibility practices as flexibility profiles is put forward here.

Overall little research on configurations of flexibility practices has been undertaken. One exception is a recent study on the basis of the European Company Survey 2009 (ECS) (Kerkhofs, Román, \& Ester, 2010). Using latent class analysis, the authors identified five flexibility clusters. The results show two profiles of high, two of moderate and one of low flexibility. The study confirms the assumption that firms fall into specific segments across and within countries. However, the variety and large number of flexibility practices investigated by Kerkhofs et al. makes it difficult to assess the results and draw general conclusions. The study also did not include external-functional flexibility activities in terms of outsourcing.

Also, from the existing literature we know little about the strategic importance of flexibility practices. Alongside with many other existing approaches the ECS-study (Kerkhofs et al., 2010) comes with a major limitation: A general basis of the investigations is the measuring by the current usage on the firm-level. As pointed out above, what can be labeled as flexibility practice may serve very different purposes- e.g. the usage of TAW as such says little about its relevance to increase firm flexibility. In case flexibility is understood as something that is swiftly used to compensate for unexpected demand shifts, assessing its general strategic relevance is limited. ${ }^{3}$ While a given practice might be important for the flexibility strategy in general, it is due to the precise situation (in the moment of the survey) whether or not a practice is actually utilized. Measuring only the current usage potentially underestimates the actual strategic relevance. Therefore the attention needs to be focused on the importance of a given set of flexibility practices for the actual purpose to gain flexibility on the firm-level.

\section{Identifying and analyzing flexibility profiles}

Considering the conceptual foundations and existing findings, the relation of different flexibility practices in Germany is not comprehensively mapped yet. The imporatance of TAW but especially the role of outsourcing and its relation to other flexibility practices remains unspecified. According to the conceptual considerations above and the outlined research gap a quantitative analysis of establishment data was conducted.

\subsection{Data and latent class analysis (LCA)}

The quantitative analysis builds on a CATI (computer assisted telephone interview) telephone survey which was conducted in the second half of 2010. The sampling criteria included the following characteristics: all German establishments with more than 20 insurable employees ("sozialversicherungspflichtige Beschäftigte"), more than three years old and from either (a) four subcategories of manufacturing, (b) information and communication (I\&C) industry or (c) financial and insurance activities (FIA) industry (according to NACE Rev. 2, see eurostat, 2008). To oversample larger establishments a stratified sampling procedure was employed using industry codes and three size classes (20-49, 50-249, 250 and more). The attained response rate was about 21.1 percent

The so-called reference date method ("Stichtagsmethode"), for example used in the IABestablishment panel, is the $30^{\text {th }}$ of June each year. 
and the retrieved $\mathrm{N}$ comprises about 990 valid cases. Limited by the mentioned sampling criteria the retrieved data set is representative for Germany. ${ }^{4}$

The empirical strategy pursued here follows the methodological agenda of organizational configuration research. However, the default method of clustering (cf. Fiss, 2007) comes with substantial weaknesses (Wiggins \& Ruefli, 1995). Recent developments of latent class analysis (LCA) have provided statistical tools that outperform common cluster analysis (Magidson \& Vermunt, 2002). Additionally, external dependencies of the configurations in question can be modeled using covariates (Collins \& Lanza, 2010). The same method can also account for potential bias due to stratified complex survey data.

As a consequence of the methodological argument made in the previous section, the analysis needs to be based on indicators that relate particular flexibility practices to an explicit gain of flexibility. Also the critique above demands a measurement of the importance rather than the current usage in order to complement existing findings. In the CATI questionnaire the respondents were asked to evaluate the importance of several flexibility practices in situations of workload change. This included: (a) flexibility via working time arrangements, (b) flexibility via shifting workers between workplaces, (c) flexibility via outsourcing of previously internally provided functions and (d) flexibility via TAW. The answer scale ranges from one to six - with one indicating "very important" and six "not important".

Latent class analysis was performed in order to reveal distinct profiles (Eid, Langeheine, \& Diener, 2003; Geiser, Lehmann, \& Eid, 2006; for variable descriptions see Table 5, Appendix). To account for the stratified sample property of the data base and to control for basic determinants of the classes, covariates were introduced (establishment size, industry, establishment is an independent firm or part of a larger corporation). ${ }^{5}$ The calculated class solutions were evaluated on the basis of several criteria. In accordance with current literature, the sample adjusted BIC value was used to determine the final number of classes (see Nylund, Asparouhov, \& Muthén, 2007). The results suggest a four-class solution to be best suited.

\subsection{LCA results: Four flexibility profiles}

The basic characteristics of the four profiles proposed by the LCA are depicted in Table 2. A summary of flexibility dimensions and identified profiles is depicted in Table 3 and in Table 4 additional information on industry and size distributions is reported. The characteristics of the identified flexibility profiles can be summarized as follows:

$4 \quad$ The original sample covers 10 percent and the realized sample covers about 2 percent of the whole underlying population. Cells that were filled with less than 20 cases at the midpoint of the survey process were oversampled to realize sufficient numbers.

5 To obtain stable LCA model solutions, the original 1-6 scale used in the questionnaire was simplified to a 1-3 scale combining two scale steps each (important: 1, 2; undecided: 3, 4; not important: 5,6$)$. 
Table 2: Flexibility profiles and means of importance by flexibility practices (standardized results)

\begin{tabular}{lcccc}
\hline & \multicolumn{2}{c}{ Profiles } & & \\
\cline { 2 - 4 } & Dual & Internal & Low & External \\
\hline Flexibility practices & & & & \\
(a) Working Time flexibility & 0.6 & 0.2 & -1.2 & -1.2 \\
(b) Shifting of workers between workplaces & 0.2 & -0.1 & -0.6 & -0.5 \\
(c) Flexibility via outsourcing & 0.3 & -0.4 & -0.5 & 0.2 \\
(d) Flexibility via Temporary Agency Work & 0.7 & -1.1 & -1.1 & 0.6 \\
\hline
\end{tabular}

Source: CATI Data Set 2010, own calculation of means by flexibility profiles. For purpose of interpretation variables where transformed. Table includes standardized variables [zero equals average value of variable], with reversed coding [higher value: higher importance; lower value: lower importance]. Bold print: for emphasis of relevant differences for interpretation

Table 3: Flexibility profiles by flexibility dimensions

\begin{tabular}{lcc} 
& \multicolumn{2}{c}{ External flexibility } \\
\cline { 2 - 3 } & High & Low \\
\hline Internal flexibility & Dual flexibility profile & Internal flexibility profile \\
High & External flexibility profile & Low flexibilityprofile \\
\hline
\end{tabular}

Source: Own depiction

Table 4: Distribution of flexibility profiles across industries (in percent)

\begin{tabular}{|c|c|c|c|c|c|}
\hline & \multicolumn{5}{|l|}{ Profiles } \\
\hline & Dual & Internal & Low & External & Total \\
\hline \multicolumn{6}{|l|}{ Industry } \\
\hline Manufacturing "M_1" [NACE: C 10-12] & 22 & 62 & 0 & 15 & 100 \\
\hline Manufacturing "M_2" [NACE: C 13-18] & 42 & 44 & 0 & 14 & 100 \\
\hline Manufacturing "M_3" [NACE: C 19-25] & 53 & 30 & 0 & 16 & 100 \\
\hline Manufacturing "M_4" [NACE: C 26-33] & 56 & 33 & 1 & 10 & 100 \\
\hline Information and Communication "I\&C" & 9 & 36 & 46 & 9 & 100 \\
\hline \multirow[t]{3}{*}{ Financial and Insurance Activities "FIA" } & 4 & 0 & 93 & 3 & 100 \\
\hline & \multicolumn{5}{|l|}{ Profiles } \\
\hline & Dual & Internal & Low & External & Total \\
\hline \multicolumn{6}{|l|}{ Size } \\
\hline 20-49 employees & 29 & 48 & 15 & 9 & 100 \\
\hline 50-249 employees & 48 & 20 & 19 & 13 & 100 \\
\hline $250+$ employees & 66 & 12 & 8 & 14 & 100 \\
\hline $\begin{array}{l}\text { Percent of } \\
\text { all cases in the sample }\end{array}$ & 40 & 33 & 16 & 11 & 100 \\
\hline
\end{tabular}

Source: CATI Data Set 2010, weighted results, own calculation. Bold print: largest share in category. Note: Differences in "Total" column due to rounding. Full names of industries and NACE codes: M_1 [NACE: C 10-12] Manufacture of Food Products, Beverages and Tobacco; M_2[NACE: C 13-18] Manufacture of Textiles, Wood, Paper; M_3 [NACE: C 19-25] Manufacture of Chemicals, Pharmaceutics, Rubber, Basic Metal; M_4 [NACE: C 26-33] Manufacture of Machinery and Equipment; I\&C[NACE: J] Information and Communication; FIA[NACE: K] Financial and Insurance Activities 
- Dual flexibility profile: Cases of the first class describe a flexibility profile that is determined by the highest levels of importance for all four items. Thus this profile combines the practices from the internal and external dimensions of flexibility. With about 40 percent of all cases it is also the most widespread profile. Regarding industry and size, the Dual profile is dominant in two sub-industries of manufacturing: the manufacture of Chemicals, Pharmaceutics, Rubber, Basic Metal (NACE: C 19-25) and the manufacture of machinery and equipment (NACE: C 26-33). The Dual profile is most prominent in larger establishments with more than 49 employees.

- Internal flexibility profile: In comparison the second flexibility profile displays a high importance of the two internal practices. At the same time both external practices are on average of lower importance. With 62 percent a majority of cases in the manufacture of food products, beverages and tobacco (NACE: C 10-12) is assigned to this profile. Also for one further sub-industry of manufacturing (Manufacture of Textiles, Wood, Paper - NACE: C 13-18) the Internal flexibility profile is also the most frequent profile. For cases from the I\&C industry it is the second most frequent profile with 36 percent. It is also the dominant profile for smaller establishments with 20 to 49 employees.

- Low flexibility profile: The third flexibility profile is characterized by the lowest average importance levels of all four flexibility practices in question. A major share of 93 percent of all cases from the FIA industry belongs to this profile. The Low profile also covers the majority of cases in the I\&C industry, whereas it is almost completely irrelevant in the manufacturing sector. The Low-profile cases challenge the traditional approaches as they indicate a segment of structural inflexibility in terms of the observed items. It can be found more often in smaller establishments.

- External flexibility profile: The fourth and last flexibility profile revealed by the LCA is defined by a high importance of the two external flexibility practices TAW and outsourcing. The levels of these two variables are similar to those of Dual profile cases. Yet, both internal variables show considerably lower average values. With a 11 percent share of all cases this profile is the least widespread. It is most present in larger manufacturing establishments.

These findings reported here are supported by a similar basic distribution found in the ECS-study by Kerkhofs, et al. (2010). Using different flexibility practices and a different sample, the authors also found a high/low-classification along with patterns of substantial specialization on either external or internal flexibility practices.

\subsection{MCA results: Analyzing the distribution of the four flexibility profiles}

The LCA revealed basic differences across industry and size groups. In order to revel further underlying distributions and the relations alongside other variables were mapped using a multiple correspondence analysis (MCA) (Greenacre, 1993; Le Roux \& Rouanet, 2010). This illustrates the properties of the four flexibility profiles and uncovers the segments within the observed population. 
A MCA transformed the associations of categorical variables into a two dimensional space where the proximity of values depicts the level of association - the closer, the stronger the association. In addition to industries and establishment size, further variables were introduced to account for general characteristics of the four flexibility profiles. This includes (1) whether or not the establishment is family owned or owner managed, (2) a variable measuring whether the establishment is part of a bigger company or a single establishment company and (3) a categorical variable of export share. The MCA yielded two dimensions. The $\mathrm{x}$-axis (59 percent of the inertia) predominantly accounts for the sectoral differences between manufacturing and nonmanufacturing cases. The y-axis (21 percent of the inertia) mainly points out the differences in establishment size.

Figure 1: Flexibility profile triangle (MCA plot including own drawings)

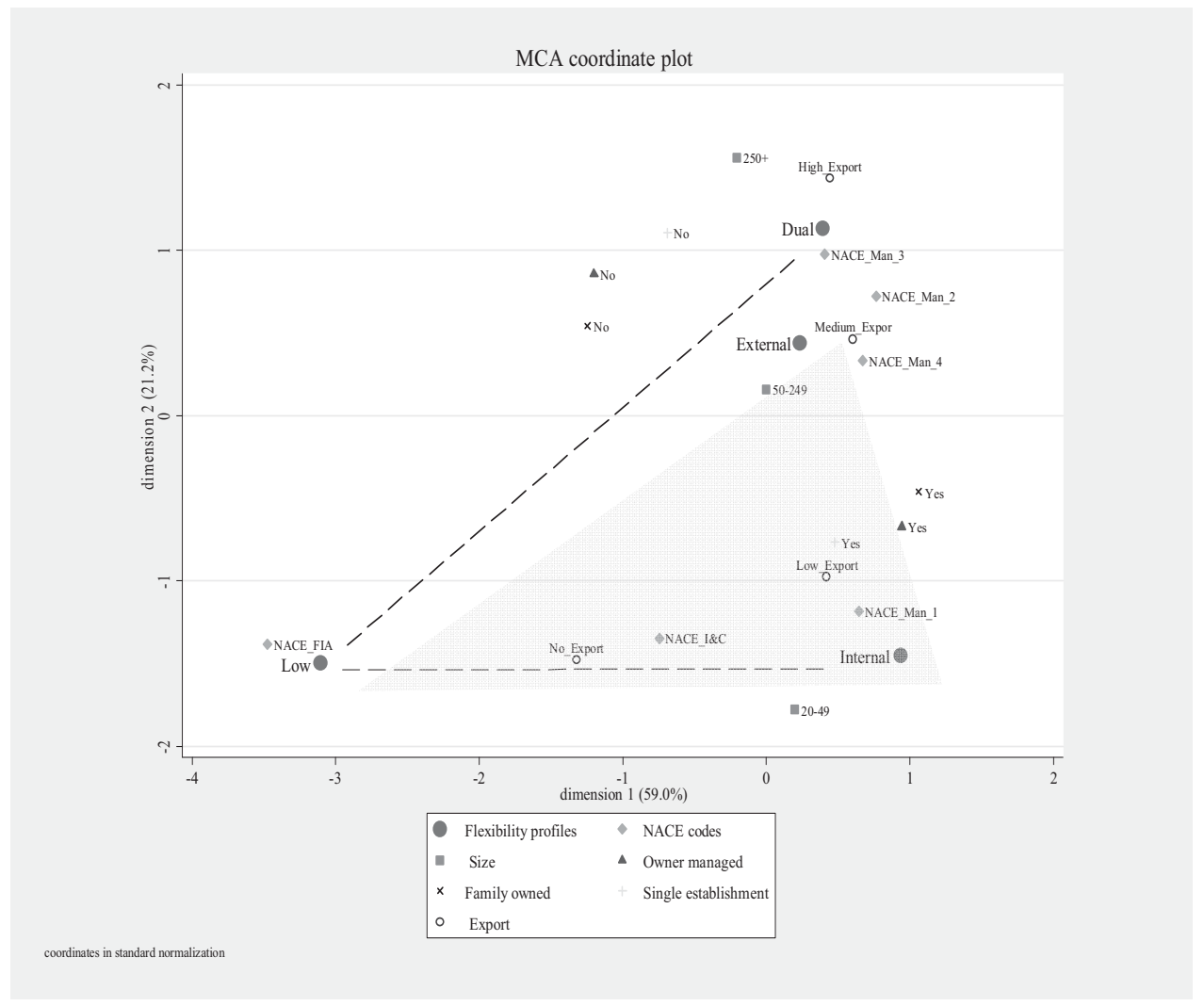

Source: CATI Data Set 2010, own calculation, original STATA plot plus grey triangle added for interpretation. Coding of Export: No Export: 0\%; Low Export: 1-15\%; Medium Export: 16-30\%; High Export: >30\%. Additional Note on MCA details: $\mathrm{N}=$ 873; Total inertia: 0.13; Method: Burt; adjusted inertias

The MCA results are depicted in Figure 1. The distribution of the different categorical outcomes roughly resembles a triangle shape. The top right corner illustrates that the Dual and External profiles are associated with larger establishments and manufactur- 
ing industries as well as increased export shares. Thus, the top end of the triangle represents the core are where the traditional German model would be expected by VoC literature. Contradicting the theoretical $\mathrm{VoC}$ assumptions, the data implies that especially large German manufacturing firms are currently using external flexibility practices. To a large extent external flexibility is here combined with internal forms in the Dual profile.

The lower right corner shows the a cluster around the Internal profile. This profile is associated with smaller, single establishment companies, owner managed and family establishments and low export shares. This indicates a particular SME approach to flexibility. In contrast to large establishments, there is evidence for an SME model that does not attribute increased importance to external flexibility. This profile relies predominantly on working time flexibility and the shifting of the workforce between workplaces. In respect to flexibility practices this profile still appears to be in line with the theoretical assumptions of the traditional German model.

In accordance with the descriptive findings presented above, there is a distinct flexibility profile outside the well-known manufacturing approaches - the Low profile in the bottom left corner. The prevalence in non-manufacturing industries indicates other flexibility practices in those domains, which are not addressed by the basic flexibility concepts employed in the CATI survey. Information and communication (I\&C) establishments are situated between the Low and the Internal profile. This reveals a tendency of an overlapping association with these two profiles in this particular industry.

\section{Conclusion}

This paper conducts a comprehensive analysis of how different flexibility practices are combined by German firms forming particular flexibility profiles. The conceptual approach builds on the VoC literature and the related research, which suggests the existence of one dominant German firm-level model focusing on internal flexibility. A latent class analysis (LCA) of four basic flexibility practices was conducted and revealed four coexisting flexibility profiles: Dual, Low, Internal and External. The findings map significant diversity within the German institutional framework.

The Dual flexibility profile cases attribute high importance to both internal and external flexibility practices. The large 40 percent share of Dual profile cases implies a widespread shift within the core areas of the German economy. This finding is substantially different to the theoretical expectations derived from the traditional German model literature. The External flexibility profile attributes similarly high importance to TAW and outsourcing. This profile also conflicts with the traditional model assumptions. The Dual and External profiles are mostly presented in larger and manufacturing cases. The findings suggest that the core of the German economy has reoriented towards new transformed path relying on external flexibility via temporary agency work and outsourcing. By combining internal and external practices, the Dual profile presumably marks an evolution from the internal flexibility focus in earlier periods. The Internal flexibility profile, however, follows the traditional mode. It can be found predominantly in smaller establishments. 
With the Low flexibility profile, a substantial manufacturing/service-industrydifferentiation was revealed. This profile can be found predominantly in the two included service sector industries. This finding implies that traditional flexibility strategies of manufacturing firms do not apply to service sector firms in the same way. The information and communication industry flexibility orientations partially overlap with those of smaller manufacturing establishments. However, the financial and insurance industry appears to follow a distinctly different flexibility model. To a certain extent, the Low flexibility profile poses a challenge to flexibility research in general because those cases do not exercise the central flexibility practices investigated in this empirical analysis.

Recent empirical findings have pointed out the significance of diversity within national economies (cf. Herrmann, 2008; Crouch et al., 2009; Lange, 2009; Aoki \& Jackson, 2008; Kirchner et al., 2012). In accordance with the conceptual approach developed in this paper, diversity of flexibility profiles is understood as an effect of distinct societal sectors within the German model. This term builds on the notion of macro or industry cultures and underlines the fact that firms are embedded in particular segments of industry and firm size. The embeddedness in different societal sectors thus explains fundamentally different approaches to flexibility in one national institutional framework. Sectors are layers underneath or across national institutional frameworks. This concept allows to account for the multi-level embeddedness in firms in a given national economy.

The results indicate that small manufacturing firms are part of a different societal sector compared to banks or large manufacturing firms. Each societal sector is characterized by a stronger or weaker relation to a specific flexibility profile. The findings show that there is a significant large/small-differentiation in terms of flexibility profiles within the manufacturing sector. This underlines critical reviews of the existing VoC literature and confirms the importance of SMEs for an empirically grounded analysis of the current German model (cf. Berghoff, 2006). With this large/smalldifferentiation along the Dual, External and Internal profiles, the results indicate the existence of a specific SME sector within the German institutional framework. Therefore it can be assumed that large and small firms each follow different development paths, which has been observed for corporate finance models as well (Deeg, 2001; Bluhm \& Martens, 2009). At the same time differences in flexibility profiles in the FIA industry and in the I\&C industry seem to reflect fundamentally different industry cultures, which also prescribe default approaches to flexibility.

The results presented also contribute to the discussion about the externalization of flexibility and a growing dualism on the German labor market. Traditionally, German firms were believed to rely on long-term employment perspectives and internal flexibility practices. With the rise of TAW and outsourcing, external flexibility was introduced into the German model. The findings presented in this paper reveal a dominant pattern and distribution on the firm-level that corresponds with the current analysis of the national institutional framework (Palier \& Thelen, 2010; Hassel, 2012). The majority of cases in the core manufacturing industries are combining internal and external flexibility practices. Far from a radical brake towards external flexibility German firms seem to have incorporated external flexibility practices into the traditional or- 
ganizational models. A question for further research will be whether external practices of flexibility might have been integrated by a process of layering (Streeck \& Thelen, 2005) combining old and new elements into a transformed German model - on an institutional as well as on a firm-level.

\section{References}

Abrahamson, E., \& Fombrun, C.J. (1994). Macrocultures: Determinants and consequences. The Academy of Management Review, 19(4), 728-755.

Ahlers, E., Öz, F., \& Ziegler, A. (2007). Standortverlagerung in Deutschland - einige empirische und politische Befunde. Düsseldorf: Hans-Böckler-Stiftung.

Albert, M. (1992). Kapitalismus contra Kapitalismus. Frankfurt a.M.: Campus.

Alewell, D., \& Hauff, S. (2011). Make-or-buy decisions regarding temporary agency work - an empirical analysis of the decision process and expected effects. The International Journal of Human Resource Management, 22(15), 3127-3145.

Amable, B. (2003). The diversity of modern capitalism. Oxford: Oxford University Press.

Aoki, M., \& Jackson, G. (2008). Understanding an emergent diversity of corporate governance and organizational architecture: An essentiality-based analysis. Industrial and Corporate Change, 17(1), 1-27.

Ashford, S.J., George, E., \& Blatt, R. (2007). Chapter 2: Old assumptions, new work - The opportunities and challenges of research on nonstandard employment. The Academy of Management Annals, 1, 65117.

Atkinson, J. (1984). Flexibility, uncertainty and manpower Management IMS Report No.89. Brighton: Institute of Manpower Studies.

Barry, M., \& Nienhueser, W. (2010). Coordinated market economy/liberal employment relations: Low cost competition in the German aviation industry. The International Journal of Human Resource Management, 21(2), 214-229.

Bellmann, L., Hohendanner, C., \& Kühl, A. (2008). Leiharbeit und Befristungen international: Vorfahrt für ungebremstes Wachstum? LAB-Forum(1), 32-37.

Berghoff, H. (2006). The End of Family Business? The Mittelstand and German Capitalism in Transition, 1949-2000. Business History Review, 80(2), 263-295.

Beyer, J. (2007). Primat der Finanzmarktorientierung. Zur Logik der Auflösung der Deutschland AG. Berliner Debatte Initial, 18(4/5), 56-82.

Beyer, J., \& Höpner, M. (2003). The disintegration of organised capitalism: German corporate governance in the 1990s. West European Politics, 26(4), 179-198.

Bluhm, K., \& Martens, B. (2009). Recomposed institutions: Smaller firms' strategies, shareholder-value orientation and bank relationships in Germany. Socio-Economic Review, 7(4), 585-604.

Bosch, G., Haipeter, T., Latniak, E., \& Lehndorff, S. (2007). Demontage oder Revitalisierung? Das Deutsche Beschäftigungsmodell im Umbruch. Kölner Zeitscbrift für Soziologie und Soz̨ialpsychologie, 59(2), 318-339.

Bouncken, R.B., Bornewasser, M., \& Bellmann, L. (Eds.) (2012). Die neue Rolle der Zeitarbeit in Deutschland. München: Hampp.

Bühler, P., Cachelin, J.-L., \& Maas, P. (2010). Customer Value bei Dienstleistungen - Managementherausforderungen zwischen interner und externer Kundenorientierung. In M. Bruhn \& B. Stauss (Eds.), Serviceorientierung im Unternehmen (pp. 103-129). Wiesbaden: Gabler.

Collins, L.M., \& Lanza, S.T. (2010). Latent class and latent transition analysis: With applications in the social, behavioral, and health sciences. Hoboken, New Jersey: Wiley.

Crouch, C., Schröder, M., \& Voelzkow, H. (2009). Regional and sectoral varieties of capitalism. Economy and Society, 38(4), 654-678.

Davis-Blake, A., \& Uzzi, B. (1993). Determinants of employment externalization: A study of temporary workers and independent contractors. Administrative Science Quarterly, 38(2), 195-223.

Deeg, R. (2001). Institutional change and the uses and limits of path dependency: The case of German finance MPIfG Discussion Paper (pp. 39 S). Köln: MPIfG. 
DiMaggio, P.J., \& Powell, W.W. (1983). The iron cage revisited - Institutional isomorphism and collective rationality in organizational fields. American Sociological Review, 48(2), 147-160.

Dütsch, M., \& Struck, O. (2011). Interne und externe Flexibilität. Eine Analyse von Personalanpassungsformen anhand des IAB-Betriebspanels 2007 Working Paper. Bamberg: Universität Bamberg.

Eid, M., Langeheine, R., \& Diener, E. (2003). Comparing typological structures across cultures by multigroup latent class analysis. Journal of Cross-Cultural Psychology, 34(2), 195-210.

Esser, J., Fach, W., \& Simonis, G. (1980). Grenzprobleme des "Modells Deutschland”. Prokla, 10(3), 4063.

eurostat. (2008). NACE Rev. 2. Statistical classification of economic activities in the European Community Methodologies and working papers. Luxembourg: Office for Official Publications of the European Communities.

Fiss, P.C. (2007). A set-theoretic approach to organizational configurations. Academy of Management Review, 32(4), $1180-1198$

Gallie, D. (2007). Production regimes, employment regimes, and the quality of work. In D. Gallie (Ed.), Employment regimes and the quality of work (pp. 1-33). Oxford: Oxford University Press.

Geiser, C., Lehmann, W., \& Eid, M. (2006). Separating "rotators" from "nonrotators" in the mental rotations test: A multigroup latent class analysis. Multivariate Behavioral Research, 41(3), 261-293.

Görzig, B., Kaminiarz, A., \& Stephan, A. (2005). Wie wirkt sich Outsourcing auf den Unternehmenserfolg aus? Neue Evidenz. Schmollers Jahrbuch (Journal of Applied Social Science Studies / Zeitschrift für Wirtschafts- und Sozialwissenschaften), 125(4), 489-507.

Greenacre, M.J. (1993). Correspondence analysis in practice. San Diego: Academic Press.

Hall, P.A., \& Soskice, D. (2001). An introduction to varieties of capitalism. In P. Hall \& D. Soskice (Eds.), Varieties of capitalism: The institutional foundations of comparative advantage (pp. 1-68). Oxford: Oxford University Press.

Hall, P.A., \& Thelen, K. (2009). Institutional change in varieties of capitalism. Socio-Economic Review, 7(1), 7-34.

Hassel, A. (2012). The paradox of liberalization - Understanding dualism and the recovery of the German political economy. British Journal of Industrial Relations, Early View (Article first published online:20 SEP 2012).

Herrigel, G. (1996). Industrial constructions: The sources of German industrial power. Cambridge: Cambridge Univ. Press.

Herrigel, G. (2010). Manufacturing possibilities. Creative action and industrial recomposition in the United States, Germany, and Japan. Oxford: Oxford University Press.

Herrmann, A.M. (2008). Rethinking the link between labour market flexibility and corporate competitiveness: A critique of the institutionalist literature. Socio-Economic Review, 644), 637-669.

Hirsch-Kreinsen, H., Ittermann, P., \& Abel, J. (2012). Industrielle Einfacharbeit: Kern eines sektoralen Produktions- und Arbeitssystems. Industrielle Beriebungen, 19(2), 187-210.

Hohendanner, C., \& Bellmann, L. (2006). Interne und externe Flexibilität. WSI-Mitteilungen, 59(5), 241246.

Hohendanner, C., \& Bellmann, L. (2007). Atypische Beschäftigung und betrieblicher Flexibilisierungsbedarf. In B. Keller \& H. Seifert (Eds.), Atypische Beschäftigung - Flexibilisierung und soziale Risiken (pp. 27-43). Berlin: edition sigma.

Holst, H., Nachtwey, O., \& Dörre, K. (2010). The strategic use of temporary agency work - Functional change of a non-standard form of employment. International Journal of Action Research, 6(1), 108-138.

Jackson, G., \& Deeg, R. (2008). Comparing capitalisms: understanding institutional diversity and its implications for international business. Journal of International Business Studies, 39, 540-561.

Jürgens, U., Krzywdzinski, M., \& Teipen, C. (2006). Changing work and employment relations in German industries - Breaking away from the German model? WZB Discussion Paper. Berlin: WZB.

Kalleberg, A.L. (2001). Organizing flexibility: The flexible firm in a new century. British Journal of Industrial Relations, 39(4), 479-504.

Keller, B., \& Seifert, H. (2006). Atypische Beschäftigungsverhältnisse: Flexibilität, soziale Sicherheit und Prekarität. WSI Mitteilungen, 59(5), 235-240. 
Kerkhofs, M., Román, A., \& Ester, P. (2010). European company survey 2009: Flexibility profiles of European companies. Luxembourg: Publications Office of the European Union.

Kinkel, S., \& Lay, G. (2003). Fertigungstiefe - Ballast oder Kapital? Stand und Effekte von Out- und Insourcing im Verarbeitenden Gewerbe Deutschlands Mitteilungen aus der Produktionsinnovationserhebung. Karlsruhe: Fraunhofer ISI.

Kinkel, S., \& Maloca, S. (2010). Verlagerungsverhalten im Zeichen der Wirtschaftskrise. Produktions- und Rückverlagerungen der deutschen Industrie. Zeitschrift für wirtschaftlichen Fabrikbetrieb, 105(4), 362-368.

Kirchner, S., Beyer, J., \& Ludwig, U. (2012). Wie viel Heterogenität gibt es im ,Modell Deutschland'? Zur Verbindung von betrieblichen Beschäftigungssystemen und Profilen der Innovationsfähigkeit. Industrielle Beziebungen, 19(2), 211-235.

Kitschelt, H., \& Streeck, W. (Eds.) (2004). Germany - Beyond the stable state. London und Portland: Frank Cass.

Krause, I. (2013). Das Verbältnis von Stabilität und Flexibilität auf dem deutschen Arbeitsmarkt: Schließungs- und Flexibilisierungsprozesse betrieblicher Beschäftigungsstrukturen. Wiesbaden: Springer VS.

Lange, K. (2009). Institutional embeddedness and the strategic leeway of actors: the case of the German therapeutical biotech industry. Socio-Economic Review, 7(2), 181-207.

Le Roux, B., \& Rouanet, H. (2010). Multiple correspondence analysis. Thousand Oaks, CA: Sage.

Lengfeld, H., \& Kleiner, T.-M. (2009). Flexible Beschäftigung und soziale Ungleichheit - Eine Synthese des Stands der Forschung. Arbeit. Zeitschrift für Arbeitsforschung, Arbeitsgestaltung und Arbeitspolitik, 18(1), 46-62.

Magidson, J., \& Vermunt, J.K. (2002). Latent class models for clustering: A comparison with K-means. Canadian Journal of Marketing Research, 20(1), 36-43.

Marsden, D. (2010). The growth of extended 'entry tournaments' and the decline of institutionalised occupational labour markets in Britain CEP Discussion Paper. London: London School of Economics and Political Science.

Nienhüser, W. (2007). Betriebliche Beschäftigungsstrategien und atypische Arbeitsverhältnisse - eine Erklärungsskizze aus Sicht einer politischen Personalökonomik. In B. Keller \& H. Seifert (Eds.), Atypische Beschäftigung. Flexibilisierung und soziale Risiken (pp. 45-65). Berlin: edition sigma.

Nylund, K.L., Asparouhov, T., \& Muthén, B. (2007). Deciding on the number of classes in latent class analysis and growth mixture modeling. A Monte Carlo simulation study. Structural Equation Modeling, 14(4), 535-569.

Palier, B., \& Thelen, K. (2010). Institutionalizing dualism: Complementarities and change in France and Germany. Politics \& Society, 38(1), 119-148.

Schneider, M.R., \& Paunescu, M. (2012). Changing varieties of capitalism and revealed comparative advantages from 1990 to 2005: a test of the Hall and Soskice claims. Socio-Economic Review, 10(4), 731-753.

Schreyögg, G., \& Grieb, C. (1998). Branchenkultur - Ein neues Forschungsgebiet. In H. Glaser, E. Schröder, \& A. Werder (Eds.), Organisationen im Wandel der Märkte (pp. 364-380). Wiesbaden: Gabler.

Scott, W.R., \& Meyer, J.W. (1991). The organization of societal sectors: Propositions and early evidence. In W.W. Powell \& P.J. Dimaggio (Eds.), The new institutionalism in organizational analysis (pp. 41-62). Chicago: University of Chicago Press.

Sorge, A. (1991). Strategic fit and the societal effect: interpreting cross-national comparisons of technology, organization and human resources. Organization Studies, 12(2), 161-190.

Streeck, W. (1991). On the institutional conditions of diversified quality production. In E. Matzner \& W. Streeck (Eds.), Beyond Keynesianism. The socio-economics of production and full employment (pp. 21-61). Aldershot: Edward Elgar.

Streeck, W., \& Thelen, K. (2005). Introduction: Institutional change in advanced political economies. In W. Streeck \& K. Thelen (Eds.), Beyond continuity: Institutional change in advanced political economies (pp. 139). Oxford: Oxford University Press.

Szydlik, M. (2008). Flexibilisierung und die Folgen. In M. Szydlik (Ed.), Flexibilisierung: Folgen für Arbeit und Familie (pp. 7-22). Wiesbaden: VS Verlag.

Tüselmann, H.-J. (1996). The path towards greater labour flexibility in Germany: Hampered by past success? Employee Relations, 18(6), 28-49. 
Whitley, R. (2007). Business systems and organizational capabilities: The institutional structuring of competitive competences. Oxford: Oxford University Press.

Wiggins, R.R., \& Ruefli, T.W. (1995). Necessary conditions for the predictive validity of strategic groups: Analysis without reliance on clustering techniques. The Academy of Management Journal, 38(6), 16351656.

Wooten, M., \& Hoffman, A.J. (2008). Organizational fields: Past, present and future. In R. Greenwood, C. Oliver, K. Sahlin, \& R. Suddaby (Eds.), Handbook of organizational institutionalism (pp. 130-148). Thousand Oaks, CA: Sage.

\section{Appendix}

Table 5: Description of the manifest variables from the latent class analysis

\begin{tabular}{|c|c|c|c|c|c|c|}
\hline No & Variable name & Obs & Mean & SD & Min & Max \\
\hline 1 & Working Time flexibility* & 981 & 2.27 & 1.45 & 1 & 6 \\
\hline 2 & Shifting of workers between workplaces* & 983 & 2.81 & 1.33 & 1 & 6 \\
\hline 3 & Outsourcing* & 981 & 3.86 & 1.51 & 1 & 6 \\
\hline 4 & Temporary Agency Work* & 984 & 3.77 & 1.79 & 1 & 6 \\
\hline 5 & Industry: M_1 & 988 & 0.10 & Binary & 0 & 1 \\
\hline 6 & Industry: M_2 & 988 & 0.10 & Binary & 0 & 1 \\
\hline 7 & Industry: M_3 & 988 & 0.19 & Binary & 0 & 1 \\
\hline 8 & Industry: M_4 & 988 & 0.41 & Binary & 0 & 1 \\
\hline 9 & Industry: I\&C & 988 & 0.09 & Binary & 0 & 1 \\
\hline 10 & Industry: FIA & 988 & 0.12 & Binary & 0 & 1 \\
\hline 11 & Size: $20-49$ & 988 & 0.26 & Binary & 0 & 1 \\
\hline 12 & Size: $50-249$ & 988 & 0.46 & Binary & 0 & 1 \\
\hline 13 & Size: $250+$ & 988 & 0.29 & Binary & 0 & 1 \\
\hline 14 & Owner managed & 983 & 0.55 & Binary & 0 & 1 \\
\hline 15 & Family owned & 983 & 0.53 & Binary & 0 & 1 \\
\hline 16 & Single establishment company & 979 & 0.58 & Binary & 0 & 1 \\
\hline 17 & Profile: External & 978 & 0.13 & Binary & 0 & 1 \\
\hline 18 & Profile: Internal & 978 & 0.25 & Binary & 0 & 1 \\
\hline 19 & Profile: Dual & 978 & 0.48 & Binary & 0 & 1 \\
\hline 20 & Profile: Low & 978 & 0.14 & Binary & 0 & 1 \\
\hline
\end{tabular}

Legend: not weighted; *Importance for flexibility in case of a workload shift, (original) coding: 1: very important, 6: unimportant. Binary coding: 1: Yes, 0 : No. For industry coding see above 